\title{
Pair-bonding and parental care in cricetid rodents: a comparative study
}

\author{
Vladimir S. Gromov
}

Received: 24 August 2009 / Accepted: 5 February 2010/Published online: 17 November 2010

(C) Mammal Research Institute, Polish Academy of Sciences, Białowieża, Poland 2010

\begin{abstract}
The cricetid rodents (hamsters, voles, and gerbils) show substantial inter-specific variation in their social organization, mating strategies, and patterns of social behavior, including parental care. In the present study, behaviors related to pair-bonding and parental activities were evaluated in male-female pairs of six cricetid species (Cricetulus migratorius Pallas, 1773, Clethrionomys rutilus Pallas, 1779, Microtus arvalis Pallas, 1778, Microtus socialis Pallas, 1773, Lasiopodomys brandti Radde, 1852, and Meriones unguiculatus Milne-Edwards, 1867) observed under laboratory conditions. These species were chosen due to particular differences in their mating strategies and the spatial-and-ethological population structure (Types I-IV). The results of the study show that there is a pronounced tendency towards both reinforcement of pair-bonds and increasing rate of direct parental care, especially paternal one, when solitary or gregarious species (Types I and II-C. migratorius and $C$. rutilus) are compared with the ones living in family groups (Type III-M. arvalis and M. socialis and Type IV-L. brandti and M. unguiculatus). Parental investment of males is mainly related to additional tactile stimulation of infants. A high level of tactile stimulation of pups promotes an increase in subsequent paternal care and reinforcement of pair-bonding, and, conversely, a deficit of tactile stimulation negatively affects the development of paternal behavior and social relationships. Thus, tactile stimulation can be regarded as one of the proximate
\end{abstract}

Communicated by: Karol Zub

V. S. Gromov $(\bowtie)$

A.N. Severtsov Institute of Ecology and Evolution, Russian Academy of Sciences,

33 Leninsky prosp.,

Moscow 119071, Russia

e-mail: vsgromov@mail.ru mechanisms of socialization that plays an essential role in the evolution of sociality, i.e., transition to a family-group mode of life in rodents.

Keywords Cricetids · Parental care · Pair-bonding · Grooming Tactile stimulation

\section{Introduction}

The cricetid rodents (hamsters, voles, and gerbils) are an important group for studies of social behavior. These rodents show substantial inter-specific variation in their social organization, mating strategies, and patterns of social behavior, including parental care. Sex and species differences in parental behavior as well as proximate and ultimate mechanisms underlying them are of great interest for many zoologists and ethologists during the last decades (Bridges et al. 1974; Elwood 1975, 1983; Thomas and Birney 1979; McGuire and Novak 1984; Oliveras and Novak 1986; Gubernick and Alberts 1987; Hofmann et al. 1989; Shilton and Brooks 1989; Solomon 1993; Wang and Insel 1996; Brown et al. 1999; Lonstein and De Vries 1999, 2000; Smorkatcheva 2003; Libhaber and Eilam 2004). There are some evidences that parental care is related to rodent social organization and mating strategies. In general, sole maternal care is the most frequent pattern associated with promiscuity, while biparental care is associated with monogamy, although not always (Kleiman 1977; Wang and Insel 1996).

Parental behavior in rodents can be divided into direct and indirect forms (Kleiman 1977). Direct parental behavior includes responsiveness to young such as nursing, huddling over, grooming (licking), retrieving, and side-byside contact with litter. Indirect parental behavior involves nest-building and maintenance as well as protection from 
predators or conspecific individuals. Parental responsiveness has been studied in many rodent species (see above references). However, housing and observation conditions were various in different laboratories, and not all the parental behavior forms were evaluated in a one general manner. Moreover, previous studies provide conflicting information on the paternal responsiveness (see, for example, Hartung and Dewsbury 1979; Wilson 1982; McGuire and Novak 1984; Oliveras and Novak 1986; Solomon 1993). Available reviews of rodent parental behavior (Hartung and Dewsbury 1979; Dewsbery 1985; Wang and Insel 1996; Lonstein and De Vries 2000) do not evaluate behaviors related to pair-bonding, and do not focus on such an important care-giving activity as grooming pup that obviously has a great importance as one of proximate mechanisms of evolution towards sociality in rodents (Gromov 2009b). In such a contingency, correct interspecies comparison based upon published data is very difficult, if possible at all.

The goal of the present study is to evaluate inter-specific differences in pair-bonding and parental activities of six representatives of family Cricetidae inhabiting Eastern Europe, Urals, Siberia, and Central Asia: gray hamster Cricetulus migratorius Pallas, 1773, red-backed vole Clethrionomys rutilus Pallas, 1779, common vole Microtus arvalis Pallas, 1778, social vole Microtus socialis Pallas, 1773, Brandt vole Lasiopodomys brandti Radde, 1852, and Mongolian gerbil Meriones unguiculatus Milne-Edwards, 1867. These species were chosen due to particular differences in their mating strategies and the spatial-andethological population structure (SEPS). According to previously developed classification (Gromov 2005a, 2008), the SEPS in rodents could be divided into four main types. Type I means lack of social groups in solitary dwellers except of temporary and unstable aggregations of males competing for females during the reproductive season only. Type II represents multi-male-multi-female breeding colonies existing due to overlapping home ranges not only during the reproductive seasons. Type III is characteristic of species with relatively stable reproducing pairs and weakly consolidated family groups with early offspring dispersal. Type IV represents structural family groups with delayed offspring dispersal and complicated social organization related, for example, to hierarchy of subordination, differentiation of behavioral roles, suppression of reproduction in offspring, etc. Gray hamster is a solitary species (Type I) with sole maternal care and promiscuous mating (Gromov et al. 2006; Gromov 2008). Red-backed vole is a gregarious species (Type II) with promiscuous mating and very weak paternal responsiveness that means mainly sole maternal care (Gromov 2008, 2009a). Reproducing pairs and weakly consolidated family groups with biparental care of young and early offspring dispersal (Type III) are characteristic of common and social voles (Gromov 2007, 2008). Both Brandt vole and Mongolian gerbil (Type IV) live in family groups with delayed offspring dispersal and complicated social structure (Gromov 2003, 2005b, 2008).

For the comparative analysis, data of the preliminary studies of the parental behavior and related activities were used (Gromov 2005b, 2007, 2008, 2009a, b; Gromov et al. 2006). In this article, I try to answer the questions: are the differences between the species under study essential? Is there a correlation of a particular type of the SEPS with different parameters of pair-bonding behavior and parental activities, and, in its turn, of pair-bonding behavior with parental behavior?

\section{Material and methods}

Animals and housing conditions

Subjects were 3rd- to 5th-generation of 3-4-month old, laboratory-bred descendants of stocks originally captured in the wild. Observations were carried out on ten primiparous females and their male mates of every species. All the animals used in the study were in good physical condition. Males were marked by clipping the spot of fur on their backs. Observations were conducted during several years (2003-2008) in spring and summer months (May-August). Both laboratory and observation conditions were identical for all reproducing pairs housed in $60 \times 35 \times 20$-cm plastic cages with wooden nest chamber and wood shavings as bedding. All the animals were maintained on natural (uncontrolled) photoperiod and fed ad lib on mixture of oats, sunflower seeds, and fresh vegetables (carrot, cabbage, and beetroots); additionally, they were provided with fresh grass. When the females were nearing parturition (47 days before birth of the litter), each pair of voles was transferred into a $60 \times 30 \times 35$-cm glass terrarium with two wooden nest chambers $(15 \times 12 \times 8 \mathrm{~cm})$ and wood shavings for bedding. For every gray hamster female and each pair of Mongolian gerbils, a $70 \times 35 \times 35-\mathrm{cm}$ glass terrarium was used with nest chambers of $20 \times 15 \times 10 \mathrm{~cm}$ in size because these animals are larger than voles. Nest chambers have transparent plastic tops to allow direct observation of the animals. The terrariums were placed in a quiet, warm room $\left(20 \pm 3^{\circ} \mathrm{C}\right)$ with natural (uncontrolled) illumination during the whole observation period, and at the dark time, additionally illuminated with an electric lamp with a power of $25 \mathrm{~W}$ fixed at a height of $1 \mathrm{~m}$ above the terrariums.

Behavioral observations

All observations started within the period from 1800 to 2400 hours, and the beginning of every next observation 
was shifted by $1-2 \mathrm{~h}$ to eliminate the effect of starting time. Animals were under observations on day 2 postpartum and thereafter, every 1-2 days (till day 21 for gray hamsters and voles and day 24 for Mongolian gerbils), each for $1 \mathrm{~h}$ each time, so that adults with their offspring were under observation during $12 \mathrm{~h}$ in total. Time at which every parent individual left or entered nest chamber was recorded. This information was used to calculate total time spent in the nest by every adult (minutes per $1 \mathrm{~h}$ ). Besides, the following behaviors were monitored for each parent: duration of grooming (licking) of the mate and pups (seconds per $1 \mathrm{~h}$ ), frequency of manipulations with bedding in the nest chamber (per $1 \mathrm{~h}$ ), and frequency of bringing nesting material (wood shavings) into the nest chamber (per $1 \mathrm{~h}$ ). To evaluate pair-bonding, such parameters as time that females shared natal nest with their male mates (minutes per $1 \mathrm{~h}$ ) and duration of the mate grooming for both partners (seconds per $1 \mathrm{~h}$ ) were used. Description of the methods is published elsewhere in detail (Gromov 2005b, 2007, 2009a, b; Gromov et al. 2006).

\section{Data analysis}

For the inter-specific comparison, a mean value of every parameter over the $12 \mathrm{~h}$ of observation for each adult was calculated; subsequently, mean values for males and females of every species under study were evaluated. Since not all the variables were normally distributed, Wilcoxon matched pairs test was used to assess sex differences among the species under study. Kruskal-Wallis ANOVA was used for the overall and multiple comparisons with Bonferroni correction to evaluate significance of differences between the species and to assess a relationship between the types of SEPS (I-IV) and both pair-bonding behavior and parental responsiveness. In the latter case, samples of species belonging to the same type of SEPS (i.e., M. arvalis and M. socialis, Type III, as well as $L$. brandti and M. unguiculatus, Type IV) were united. To evaluate a relationship between different parameters of parental and pair-bonding behavior, Spearman's rank order correlations were calculated between all the variables (Sokal and Rohlf 1995). In addition, a cluster analysis of all the variables with use of the Euclidean distance as a measure of single linkage was conducted to present the results in a graphic form.

\section{Results and discussion}

Pair-bonding

Among the species under study, average values of such a parameter as duration of mate grooming displayed by males were found to be greater than values of the same parameter in females (Table 1), but sex differences were significant in two species only: $M$. socialis (Wilcoxon test, $Z=2.803, p=$ 0.005 ) and $M$. unguiculatus (Wilcoxon test, $Z=2.547, p=$ $0.011)$.

Inter-species differences were found to be significant both for mate grooming by females (Kruskal-Wallis test, overall comparison, $H_{5},{ }_{60}=37.024, p=0.00045$ after Bonferroni correction) and males (Kruskal-Wallis test, overall comparison, $H_{5}, 6_{0}=49.945, p=0.00015$ after Bonferroni correction). Results of multiple comparisons are shown in Table 2. Males of two species living in family groups (M. socialis and M. unguiculatus) were revealed to groom their female mates significantly longer than did males of C. rutilus and M. arvalis. As for the latter, it needs to note that common voles live in unstable (weakly consolidated) family groups with relatively weak pairbonds (Zorenko 1994), and social structure of this species essentially differs from that of other rodent species with family-group mode of life, and even from $M$. socialis belonging to the same type of SEPS (III). Relatively weak pair-bonding in common vole brings this species together with gregarious ones like C. rutilus, and this is reflected in a lack of difference in some indexes between these two species (Table 2, as well as Tables 3 and 4).

Analysis of variance showed a significant difference between the types of SEPS related to such a parameter of pair-bonding as mate grooming by males (Kruskal-Wallis test, overall comparison, $H_{3}, 60=34.692, p=0.00031$ after Bonferroni correction). Additionally, a high positive correlation was found between the types of SEPS and mate grooming by males, Spearman's $R=0.716, t_{(N-2)}=$ 7.946, $p=0.0000001$ (see also Fig. 1).

As for mate grooming by female, inter-species differences related to this pair-bonding behavior were found to be not so pronounced (Table 2): M. socialis females only were revealed to groom their male mates significantly longer than did females of $C$. rutilus and M. arvalis. Nevertheless, analysis of variance has shown a significant difference between the types of SEPS concerning mate grooming by females (Kruskal-Wallis test, overall comparison, $H_{3,60}=$ 26.727, $p=0.00067$ after Bonferroni correction). The types of SEPS are also positively correlated with such a parameter of pair-bonding as mate grooming by females, Spearman's $R=0.576, t_{(N-2)}=5.454, p=0.000001$.

Inter-specific differences concerning third registered parameter related to pair-bonding (nest residence with mate) were found to be significant as well (Kruskal-Wallis test, overall comparison, $H_{5,60}=47.084, p=0.00011$ after Bonferroni correction). Results of multiple comparisons are shown in Table 3: reproducing pairs of all the species living in family groups (M. arvalis, M. socialis, L. brandti, and M. unguiculatus) spent longer time together in the nest than did mates of C. rutilus; besides, mates of $M$. socialis and $L$. 
Table 1 Mean values $(M \pm S E)$ of parental and related activities in six cricetid rodents with different types of the spatial-and-ethological population structure (I-IV)

\begin{tabular}{|c|c|c|c|c|c|c|}
\hline Sex and behaviors & $\begin{array}{l}\text { C. migratorius } \\
\text { I }\end{array}$ & $\begin{array}{l}\text { C. rutilus } \\
\text { II }\end{array}$ & $\begin{array}{l}\text { M. arvalis } \\
\text { III }\end{array}$ & $\begin{array}{l}\text { M. socialis } \\
\text { III }\end{array}$ & $\begin{array}{l}\text { L. brandti } \\
\text { IV }\end{array}$ & $\begin{array}{l}\text { M. unguiculatus } \\
\text { IV }\end{array}$ \\
\hline \multicolumn{7}{|l|}{ Females: } \\
\hline Total nest residence ${ }^{a}$ & $37.1 \pm 3.0$ & $43.8 \pm 1.9$ & $49.1 \pm 1.7$ & $51.9 \pm 1.0$ & $53.2 \pm 1.0$ & $45.1 \pm 2.9$ \\
\hline Nest residence with the mate ${ }^{a}$ & 0 & $15.8 \pm 4.6$ & $39.6 \pm 3.1$ & $47.3 \pm 0.7$ & $50.5 \pm 1.2$ & $36.7 \pm 3.6$ \\
\hline Mate grooming ${ }^{b}$ & 0 & $0.2 \pm 0.1$ & $2.9 \pm 0.9$ & $10.5 \pm 2.5$ & $9.3 \pm 2.7$ & $6.0 \pm 1.4$ \\
\hline Pup grooming ${ }^{b}$ & $78.2 \pm 13.1$ & $91.4 \pm 8.9$ & $110.1 \pm 9.5$ & $164.2 \pm 25.2$ & $79.4 \pm 9.3$ & $109.4 \pm 17.7$ \\
\hline Manipulations with bedding ${ }^{c}$ & $13.3 \pm 1.7$ & $12.2 \pm 2.6$ & $4.4 \pm 1.4$ & $0.7 \pm 0.4$ & $6.1 \pm 1.4$ & $2.6 \pm 0.6$ \\
\hline Bringing nesting material ${ }^{c}$ & $0.5 \pm 0.1$ & $3.9 \pm 1.7$ & $1.1 \pm 0.7$ & $0.1 \pm 0.1$ & $1.8 \pm 0.3$ & $0.6 \pm 0.5$ \\
\hline \multicolumn{7}{|l|}{ Males: } \\
\hline Total nest residence ${ }^{a}$ & 0 & $20.7 \pm 6.1$ & $46.9 \pm 2.8$ & $54.7 \pm 0.8$ & $56.0 \pm 0.5$ & $47.7 \pm 2.4$ \\
\hline Mate grooming ${ }^{\mathrm{b}}$ & 0 & $3.7 \pm 1.5$ & $6.0 \pm 1.6$ & $32.2 \pm 4.7$ & $16.1 \pm 5.1$ & $34.6 \pm 5.8$ \\
\hline Pup grooming ${ }^{b}$ & 0 & $10.5 \pm 4.2$ & $31.1 \pm 4.6$ & $86.5 \pm 12.3$ & $38.5 \pm 8.2$ & $109.6 \pm 21.8$ \\
\hline Manipulations with bedding ${ }^{\mathrm{c}}$ & 0 & $1.7 \pm 0.7$ & $0.9 \pm 0.4$ & $0.5 \pm 0.2$ & $1.9 \pm 0.5$ & $2.2 \pm 1.0$ \\
\hline Bringing nesting material ${ }^{\mathrm{c}}$ & 0 & 0 & 0 & 0 & $0.7 \pm 0.5$ & $0.1 \pm 0.1$ \\
\hline
\end{tabular}

${ }^{\mathrm{a}}$ Duration (minutes per $1 \mathrm{~h}$ )

${ }^{\mathrm{b}}$ Duration (seconds per $1 \mathrm{~h}$ )

${ }^{\mathrm{c}}$ Frequency (number of occurrences per $1 \mathrm{~h}$ )

brandti significantly differed from mates of $M$. arvalis and M. unguiculatus due to higher values of this parameter. Analysis of variance has also shown a significant difference between the types of SEPS related to nest residence with mate (Kruskal-Wallis test, overall comparison, $H_{3}, 60=$ 37.170, $p=0.00024$ after Bonferroni correction). Additionally, a high positive correlation was found between the types of SEPS and such a parameter as nest residence with mate, Spearman's $R=0.699, t_{(N-2)}=7.588, p=0.0000005$ (see also Fig. 2).

To summarize, the weakest pair-bonding is characteristic of C. migratorius (Type I) in which males do not have contact with pregnant and lactating females. Males of species living in family groups (especially that ones belonging to Type IV like $M$. unguiculatus) display a higher rate of activity related to the female mate's grooming than do males of C. rutilus (Type II). Moreover, grooming of the female mate by males is considerably more prolonged than grooming of the male mate by females (Table 1). Besides, the reproducing pairs in species living in family groups (Type III and Type IV) spent longer time together in the nest than did males and females of C. rutilus (Type II). These inter-specific differences reflect reinforcement of pair-bonds in rodents with family-group mode of life (Types III and IV) compared to solitary (Type I) or gregarious ones (Type II).

Direct parental behavior

As mentioned above, C. migratorius males do not display the direct parental behavior at all. As for other species under study, sex differences in the nest attendance were revealed in C. rutilus, M. socialis, and L. brandti. The females of $C$. rutilus spent significantly longer time in the

Table 2 Multiple comparisons (Kruskal-Wallis ANOVA) for six cricetid rodents

\begin{tabular}{|c|c|c|c|c|c|c|}
\hline & C. migratorius & C. rutilus & M. arvalis & M. socialis & L. brandti & M. unguiculatus \\
\hline C. migratorius & - & & & 0.000001 & 0.001973 & 0.000001 \\
\hline C. rutilus & & - & & 0.001612 & & 0.002533 \\
\hline M. arvalis & & & - & 0.006292 & & 0.009708 \\
\hline M. socialis & 0.000001 & 0.015330 & 0.035495 & - & & \\
\hline L. brandti & 0.000109 & & & & - & \\
\hline M. unguiculatus & 0.006476 & & & & & - \\
\hline
\end{tabular}

Above the diagonal mate grooming by males, below the diagonal mate grooming by females

Only significant $p$ values are entered in the table 
Table 3 Multiple comparisons (Kruskal-Wallis ANOVA) for six cricetid rodents

\begin{tabular}{|c|c|c|c|c|c|c|}
\hline & C. migratorius & C. rutilus & M. arvalis & M. socialis & L. brandti & M. unguiculatus \\
\hline C. migratorius & - & & 0.003670 & 0.000019 & 0.000001 & 0.039768 \\
\hline C. rutilus & & - & & 0.006785 & 0.000109 & \\
\hline M. arvalis & & & - & & & \\
\hline M. socialis & 0.007798 & & & - & & \\
\hline L. brandti & 0.000581 & 0.011228 & & & - & \\
\hline M. unguiculatus & & & & & & - \\
\hline
\end{tabular}

Above the diagonal mate grooming by males, below the diagonal mate grooming by females

Only significant $p$ values are entered in the table

nest than did males of this species (Wilcoxon test, $\mathrm{Z}=$ 2.191, $p=0.028)$. On the contrary, the females of $M$. socialis and L. brandti spent significantly less time in the nest than did males of these species; for samples with minimum difference ( $L$. brandti) Wilcoxon test, $Z=2.429$, $p=0.015$. There were no significant sex differences related to nest attendance in other species under comparison.

Inter-specific differences concerning such a parameter as total time spent in the nest by females were found to be significant (Kruskal-Wallis test, overall comparison, $H_{5}$, ${ }_{60}=25.462, p=0.0015$ after Bonferroni correction). Results of multiple comparisons (Table 3) show that females of some species living in family groups (M. socialis and $L$. brandti) spent significantly longer time in the nest than did females of $C$. migratorius and $C$. rutilus. Results of the analysis of variance support the main tendency for females of species with family-group mode of life (Types III and IV) to spend longer time in the nest compared with gregarious (Type II) or solitary (Type I) species (KruskalWallis test, overall comparison, $H_{3}, 60=17.865, p=0.003$ after Bonferroni correction). The same tendency is also supported by the correlation analysis that showed a pronounced relationship between the types of SEPS and nest residence in females, Spearman's $R=0.454, t_{(N-2)}=$ 3.947, $p=0.00021$ (see also Fig. 3).

Cross-species comparison has shown that differences concerning the nest residence in males are much more pronounced than that ones in females (Kruskal-Wallis test, overall comparison, $H_{5}, 60=47.219, p=0.00012$ after Bonferroni correction). Results of multiple comparisons (Table 4) show that males of some species living in family groups (M. socialis and L. brandti) spent significantly longer time in the nest than $C$. rutilus males. Comparison of male nest residence across the types of SEPS revealed significant differences as well (Kruskal-Wallis test, overall comparison, $\mathrm{H}_{3},{ }_{60}=37.964, p=0.00021$ after Bonferroni correction). In general, males of species with family-group mode of life (Types III and IV) spent significantly longer time in the nest than males of gregarious (Type II) and solitary (Type I) species. This conclusion is also supported by the correlation analysis, Spearman's $R=0.707, t_{(N-2)}=$ 7.775, $p=0.0000002$ (see also Fig. 4).

Sex differences in pup grooming were revealed in all the species under study except $M$. unguiculatus. Females, as a rule, were found to be more active parents in this respect than males; for samples with minimum difference ( $L$. brandti) Wilcoxon test, $\mathrm{Z}=2.428, p=0.015$.

Cross-species comparison has shown that differences in pup grooming displayed by females were insignificant (KruskalWallis test, overall comparison, $H_{5},{ }_{60}=15.627, p=0.1224$ after Bonferroni correction). Unlike females, inter-specific differences related to pup grooming exhibited by males were revealed to be very significant (Kruskal-Wallis test, overall comparison, $H_{5}, 60=49.569, p=0.00016$ after Bonferroni

Table 4 Multiple comparisons (Kruskal-Wallis ANOVA) for six cricetid rodents

\begin{tabular}{|c|c|c|c|c|c|c|}
\hline & C. migratorius & C. rutilus & M. arvalis & M. socialis & L. brandti & M. unguiculatus \\
\hline C. migratorius & - & & 0.008019 & 0.000003 & 0.000001 & 0.012282 \\
\hline C. rutilus & & - & & 0.002075 & 0.000366 & \\
\hline M. arvalis & 0.023171 & & - & & & \\
\hline M. socialis & 0.000001 & 0.000286 & & - & & \\
\hline L. brandti & 0.010978 & & & & - & \\
\hline M. unguiculatus & 0.000001 & 0.001068 & & & & - \\
\hline
\end{tabular}

Above the diagonal nest residence in males, below the diagonal pup grooming by males

Only significant $p$ values are entered in the table 


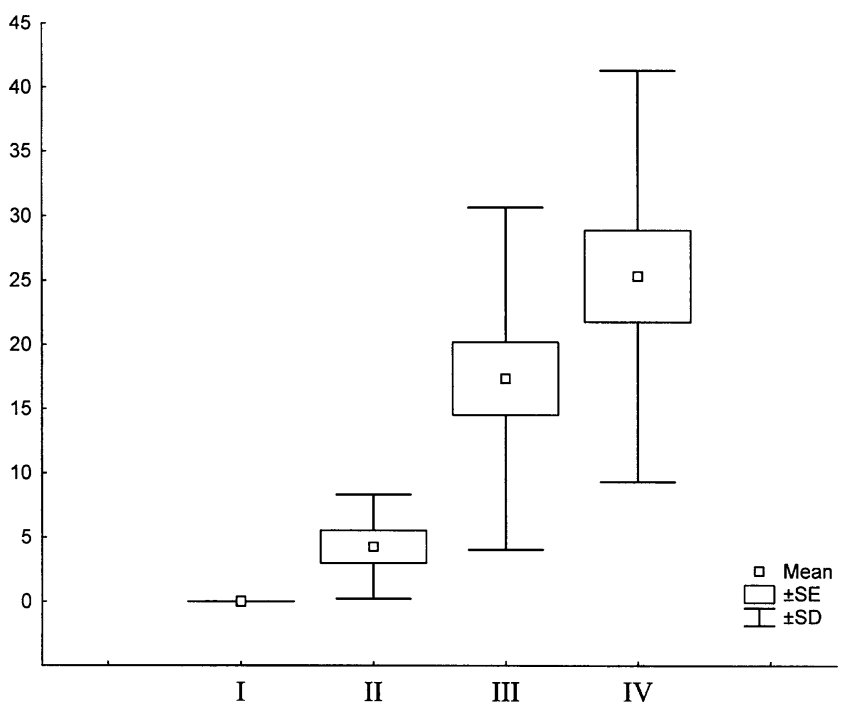

Fig. 1 Box plots showing variation in mate grooming by males (per $1 \mathrm{~h}$ ) among cricetid rodents with different types of the spatial-and ethological population structure (I-IV). Vertical axis time in seconds

correction). Results of multiple comparisons (Table 4) showed that males of some species living in family groups $(M$. socialis and $M$. unguiculatus) groom the pups longer time than do C. rutilus males. Comparison of male pup grooming across the types of SEPS revealed significant differences as well (Kruskal-Wallis test, overall comparison, $H_{3}, 60=$ 37.457, $p=0.00028$ after Bonferroni correction). As a rule, males of species with family-group mode of life (Types III and IV) groom their pups longer than do males of gregarious (Type II), and males of solitary species (Type I) do not care for their young at all. This conclusion is supported by the correlation analysis, Spearman's $R=0.689, t_{(N-2)}=7.361, p=$ 0.0000004 (see also Fig. 5).

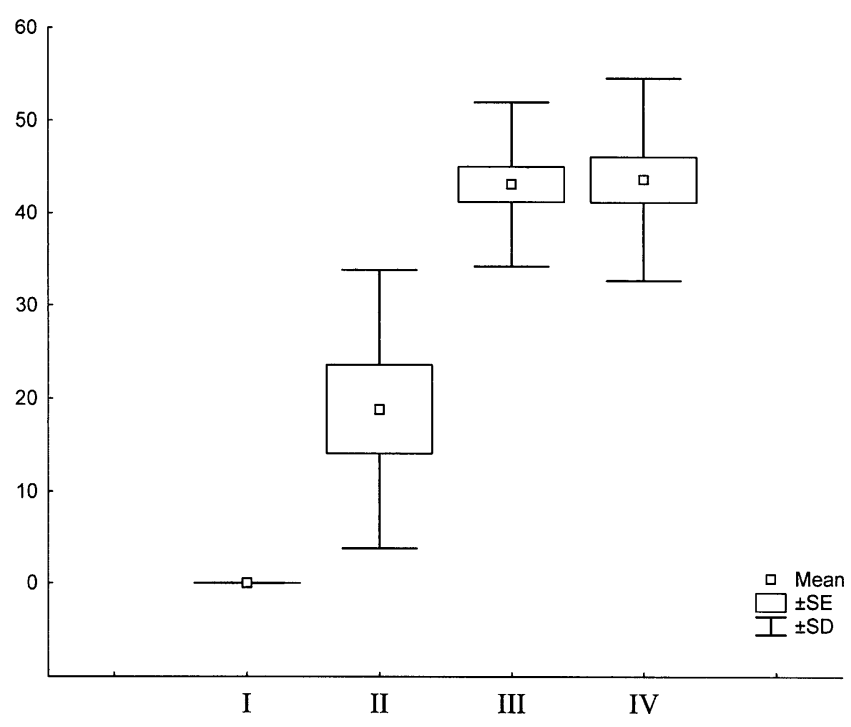

Fig. 2 Box plots showing variation in nest residence with mate (per $1 \mathrm{~h}$ ) among cricetid rodents with different types of the spatial-and ethological population structure (I-IV). Vertical axis time in minutes

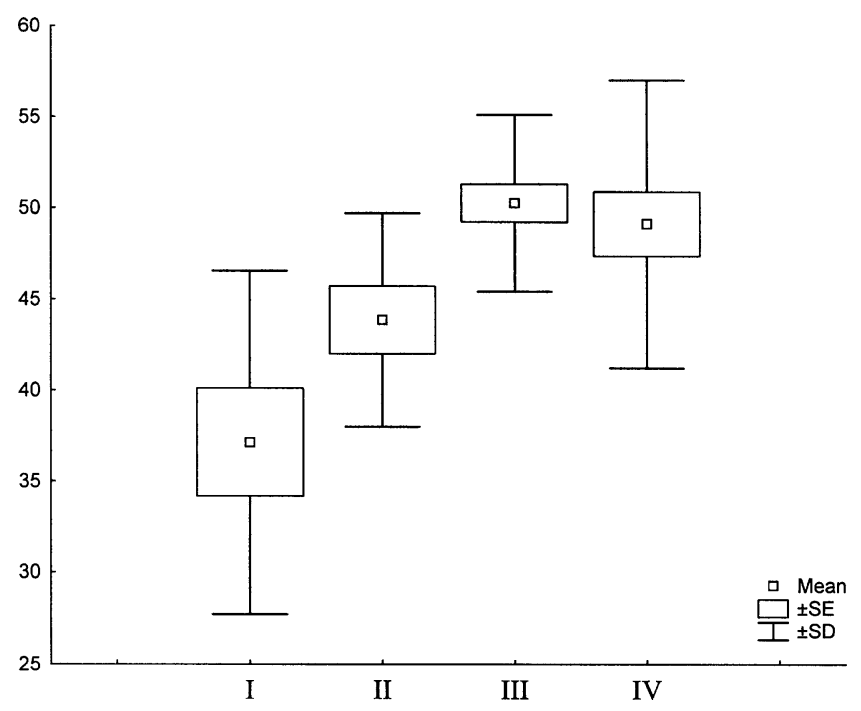

Fig. 3 Box plots showing variation in total nest residence in females (per $1 \mathrm{~h}$ ) among cricetid rodents with different types of the spatial-and ethological population structure (I-IV). Vertical axis time in minutes

To summarize, females of gray hamster (Type I) and both parents of red-backed vole (Type II) showed a significantly lower rate of direct parental care as compared to adults of the species living in family groups (Types III and IV). This difference especially concerns such male care-giving activities as nest residence and pup grooming.

Indirect parental behavior

Sex differences in indirect parental behavior were found to be not significant in $M$. socialis and M. unguiculatus as well as in L. brandti in relation to such a parameter as bringing nesting material. Other species showed significant

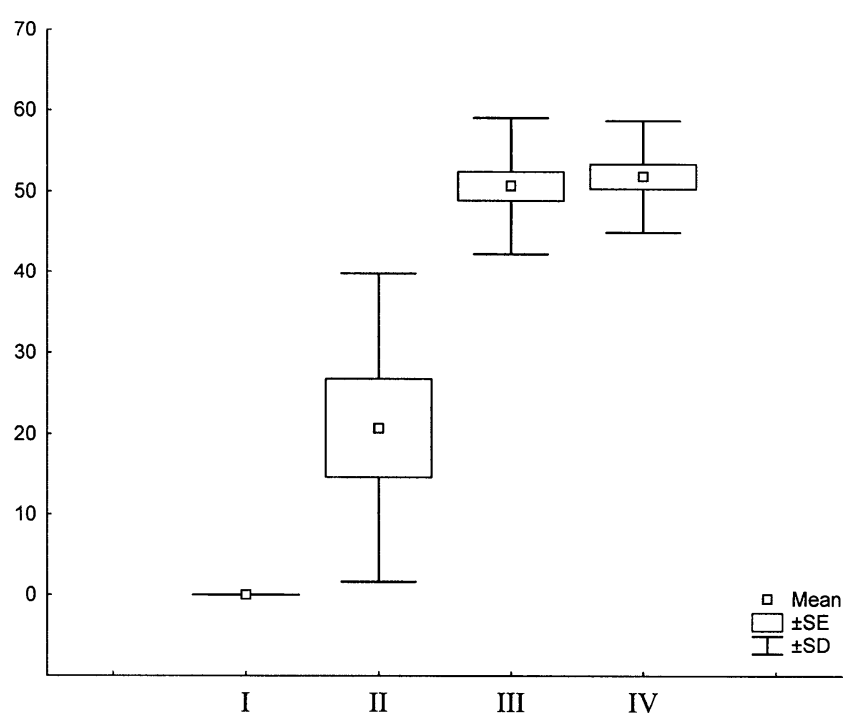

Fig. 4 Box plots showing variation in total nest residence in males (per $1 \mathrm{~h}$ ) among cricetid rodents with different types of the spatial-and ethological population structure (I-IV). Vertical axis time in minutes 


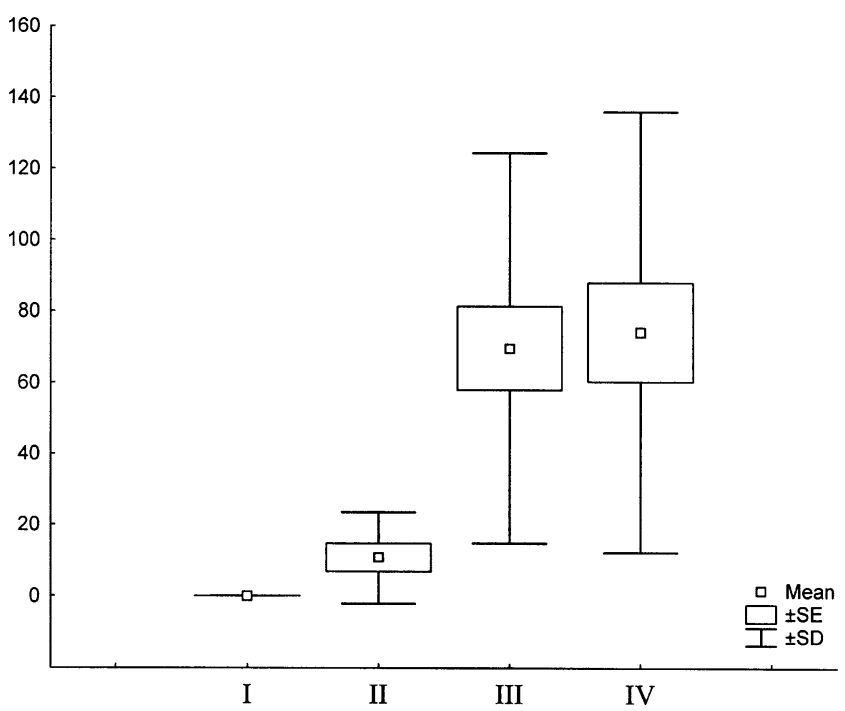

Fig. 5 Box plots showing variation in pup grooming by males (per $1 \mathrm{~h})$ among cricetid rodents with different types of the spatial-and ethological population structure (I-IV). Vertical axis time in seconds $\backslash$

sex differences, and the least ones were revealed in $M$. arvalis concerning such a parameter as bringing nesting material, Wilcoxon test, $\mathrm{Z}=2.366, p=0.018$.

An analysis of variance showed that inter-specific differences in indirect parental behavior among the rodents under study were insignificant (Kruskal-Wallis test, overall comparison, $H_{5,60}<=15.343, p>=0.1353$ after Bonferroni correction).

\section{Patterns of correlation}

There are some significant correlations among the parameters under study (Table 5, Fig. 6).

A high positive correlation is found between three parameters related to nest residence of the adults: total time spent in the nest by (1) males, (2) females, and (3) both parents together. This relationship shows that longlasting nest residence exhibited by a pregnant and especially lactating female could be a factor affecting the behavior of the male mate, and the latter could be attracted to the nest and share it with the female mate in case of nonaggressive female response. Anyway, this relationship allows speaking about that the behavior of a male depends on the response of the female mate, and thus, reflects the reinforcement of pair-bonding when solitary (Type I) or gregarious (Type II) rodent species are compared to the ones living in family groups (Types III and IV).

A positive correlation is also revealed between total time spent in the nest by males and duration of grooming of both the female mate and pups exhibited by males. Besides, duration of pup grooming by male is positively correlated with such a parameter as grooming of the female mate by the male. Results of the cluster analysis (Fig. 6) show that behaviors reflected pair-bonding (nest residence with mate and mate grooming) are highly correlated with such a parental responsiveness as nest residence both in male and female. In turn, nest residence in parent individuals is closely associated with pup grooming, especially displayed by the male. In other words, the more the time that the male spends in the nest, the more the male grooms the female mate, and the more the pups receive grooming from the male. The important conclusion is that this relationship also reflects both reinforcement of pair-bonding and increase of paternal tactile stimulation of the pups in the rodent species with family-group mode of life.

A positive correlation was also found between both indirect parental behaviors displayed by males. This means that paternal responsiveness related to nest-building and maintenance represents more concerted behaviors against the same responsiveness of females.

And finally, a high negative correlation is found between the rate of manipulations with bedding exhibited by female

Table 5 Correlation matrix of variables related to pair-bonding and parental activities (1-9)

\begin{tabular}{|c|c|c|c|c|c|c|c|c|c|}
\hline & 1 & 2 & 3 & 4 & 5 & 6 & 7 & 8 & 9 \\
\hline 1 & - & & & & & & & & \\
\hline 2 & 0.964 & - & & & & & & & \\
\hline 3 & 0.964 & 0.989 & - & & & & & & \\
\hline 4 & 0.857 & & & - & & & & & \\
\hline 5 & 0.857 & & & 0.991 & - & & & & \\
\hline 6 & & & & & & - & & & \\
\hline 7 & & & & & & & - & & \\
\hline 8 & & & & & & & 0.788 & - & \\
\hline 9 & & & & -0.893 & -0.893 & -0.786 & & & - \\
\hline
\end{tabular}

Only significant Spearman's $R$ values ( $p<$ or $=0.036$, highlighted in a bold font) are entered in the table

1 total nest residence in male, 2 total nest residence in female, 3 nest residence with mate, 4 mate grooming by male, 5 pup grooming by male, 6 pup grooming by female, 7 manipulations with bedding by male, 8 bringing nesting material by male, 9 manipulations with bedding by female 
Fig. 6 Cluster analysis of data with Euclidean distance as a measure of single linkage for all the variables indicating correlations between different behaviors related to pair-bonding and parental responsiveness. Horizontal axis linkage distance

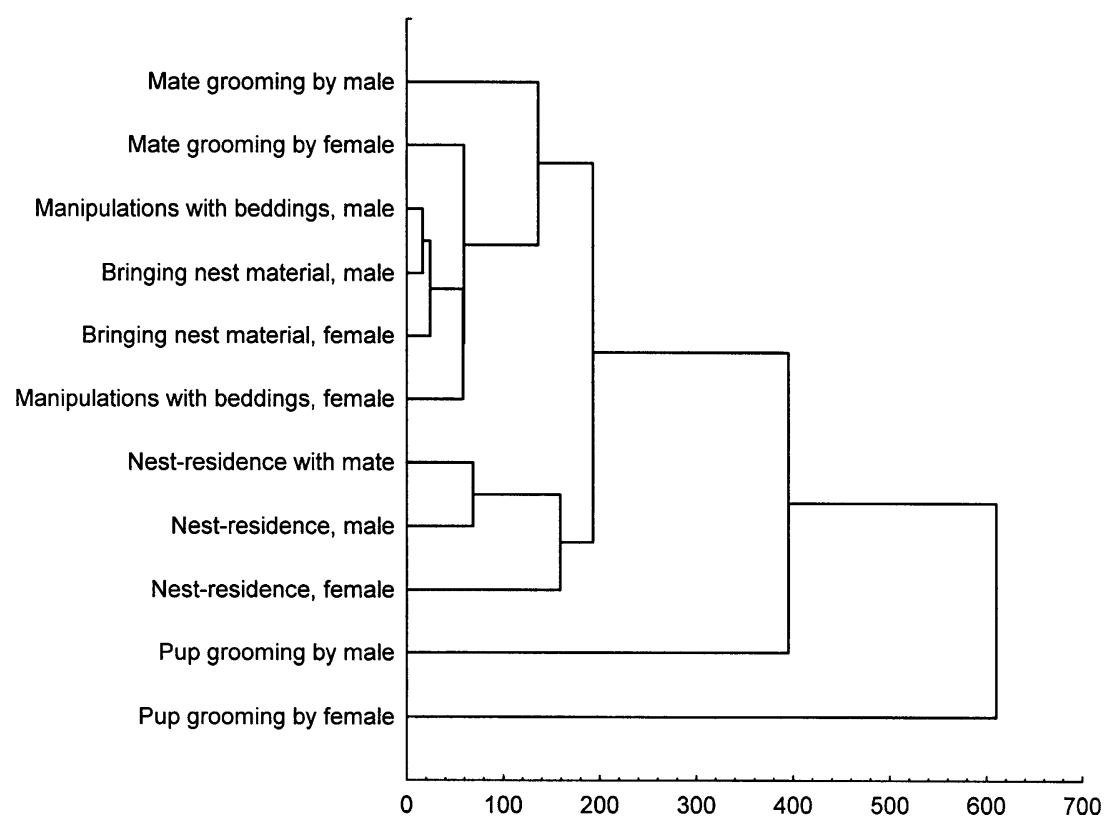

and such parameters as the mate grooming by male, pup grooming by male, and pup grooming by female. Unfortunately, it is difficult to account for the causes of these relationships.

There were no significant correlations between other registered parameters, and so, not all of these were included in Table 5 .

\section{General discussion}

The present investigation shows that, although differences between the species with various types of the SEPS are not always well expressed, there is a pronounced tendency towards both reinforcement of pair-bonds and increasing rate of direct parental care, especially paternal one, when solitary or gregarious cricetid rodents (Types I and II) are compared with the ones living in family groups (Types III and IV). It is important that sex differences in the mate grooming were revealed in the species with family-group mode of life only (Types III and IV), and males were found to be more active than females in this respect. Besides, the males of these species invested significantly more time grooming their female mates than did males of a gregarious species $C$. rutilus (Type II). It means that males obviously play a more active role in the process of reinforcement of pair-bonding among the species with family-group mode of life. Nest cohabitation of both parents and rate of the pup grooming exhibited by males was also expressed in a significantly larger extent in species with family-group mode of life compared with $C$. rutilus. These differences reflect an essentially higher parental investment of males of $M$. arvalis, $M$. socialis, $L$. brandti, and $M$. unguiculatus compared to males of $C$. rutilus and, especially, C. migratorius in which males do not care for their young at all. As a result, overall parental investment in species with family-group mode of life could be evaluated at a significantly higher level than that of gregarious species or solitary dwellers.

The present findings indicate an obvious relationship between the types of SEPS of rodents and both pair-bonding and parental responsiveness, especially the one related to the direct parental care. In essentially solitary species (Type I) like C. migratorius, males do not display care-giving activities. The same seems to be typical of many other representatives of subfamilies Cricetinae, e.g., Mesocricetus auratus (Rowell 1961), Peromyscus leucopus (Xia and Millar 1988), and Microtinae, e.g., Microtus montanus (McGuire and Novak 1986). Mainly, uniparental care is also characteristic of gregarious species (Type II) like C. rutilus, C. gapperi (McGuire 1997), or Microtus pennsylvanicus (McGuire and Novak 1984) in which males display parental responsiveness partially or occasionally only; besides, males of these species exhibit maximum variability of direct paternal care (see Hartung and Dewsbury 1979). As for rodents with familygroup mode of life, there are species that form family groups with relatively weak pair-bonds and not so high level of paternal care (Type III) like M. arvalis. On the other hand, there are species of Type IV exhibiting strong pair-bonds and a higher level of biparental care, like L. brandti or $M$. unguiculatus. The same seems to be characteristic of Microtus ochrogaster (McGuire and Novak 1984; Solomon 1993), Microtus pinetorum (McGuire and Novak 1984), and Peromyscus californicus (Gubernick and Alberts 1987).

Thus, one can say about a continuum of pair-bonding and care-giving activity related to different mating strategies and sociality in rodents associated with four main types 
of SEPS. This continuum reflects reinforcement of pairbonds and an increase of activity related to direct parental care, especially paternal one, providing a higher rate of tactile stimulation of pups due to huddling over them, sideby-side contacts, and grooming (licking). Huddling over pups was not directly estimated in the species under study. Nevertheless, such a parameter as nest residence of parent individuals can be used as an appropriate index of huddling over pups because both male and female being in the nest spend not less than $80 \%$ of time in close side-by-side and other tactile contacts with infants (Gromov 2005b, 2007; Gromov et al. 2006).

Environmental factors as well as ultimate mechanisms promoting pair-bonding and parental responsiveness are out of discussion in this article, but it is essential to note that proximate mechanisms underlying the differences between closely related species with various mating strategies, and patterns of the parental behavior, especially paternal one, could play an important role in evolution towards sociality among cricetid rodents.

Sociality means group-living. Among rodents, many marmots (Armitage 1981; Arnold 1990a, b), both castor species (Svendsen 1980; Dezhkin et al. 1986), muskrat (Proulx and Gilbert 1983), some voles and gerbils (Ågren et al. 1989; Carter and Getz 1993; Smorkatcheva 2003; Gromov 2003, 2007) are considered social ones like many others (Gromov 2008), and all of them live in family groups and exhibit nest cohabitation, cooperation in different activities, and biparental care of young. Thus, evolution towards sociality in rodents could be imagined as a pathway to family-group mode of life, or, in other words, a progressive evolutionary transformation of the SEPS of Type I into Type IV. Environmental conditions seem to play a decisive role as trigger stimuli for evolution towards sociality, but other factors, especially social ones, perhaps, are also very important and deserve special consideration.

One of the previous studies (McGuire 1988) showed that young of meadow vole (M. pennsylvanicus) reared by prairie vole parents $(M$. ochrogacter) received more parental contacts than pups fostered to meadow vole parents. When tested in adulthood, cross-fostered females spent more time in the nest and exhibited more brooding and pup grooming than in-fostered females; cross-fostered males often entered the natal nest and engaged in more pup contact behavior than in-fostered males, in that number brooding and grooming pups. Another study (Gromov 2009b) has shown that young Mongolian gerbils reared in incomplete family groups (without adult male) exhibited a lower rate of subsequent parental responsiveness related to nest attendance and grooming pups; besides, males of the experimental group groomed their female mates significantly less frequently than did males of the control group.
These results suggest that development of parental behavior, especially paternal one, is subject to influence by characteristics of the early environment.

In the rodent species with family-group mode of life, parental investment of males is mainly related to brooding and licking pups providing for additional tactile stimulation of infants. Licking young, which is considered as part of grooming (McGuire and Novak 1984, 1986; Solomon 1993), facilitates blood circulation of infants and in turn supports thermoregulation and activates the infants (Eilam and Smotherman 1998). Besides, licking the ano-genital region of pups induces them to urinate and defecate (Rosenblatt and Lehrman 1963). Although pup grooming decreased during postnatal development, it did not disappear entirely at weaning in species with the family-group mode of life (Gromov 2005b, 2007, 2009a, b), when the above functions were no longer required. Therefore, pup grooming probably has an additional, social role, in maintaining the bond between parents and offspring.

Above-mentioned experiments with pups of meadow vole (M. pennsylvanicus) fostered to prairie vole parents (M. ochrogaster) suggest the importance of early experience for acquiring patterns of parental care, especially paternal one. One can say that young males "inherit" the stereotype of parental behavior of adult male: if adult male exhibits increased parental care, the "careful father" behavioral stereotype is fixed in young individuals, and vice versa (McGuire 1988; Roberts et al. 1998). In our experiments with Mongolian gerbils (Gromov 2009b), a quite expected effect was obtained: young males that had no contact with adult male, after reaching sexual maturity, cared for their own pups to a lesser degree than "normal" males that grew in families with two parents. Similar transformation of parental behavior that occurs not only in males but in females also can fix and intensify within several generations, and this phenomenon has undoubtedly an epigenetic nature (Francis et al. 1999).

The role of tactile stimulation in the formation of complicated social organization of rodents has almost not been studied. However, the data concerning neurobiological basis of parental care indicate the critical importance of tactile stimulation for understanding inter-specific differences in parental care. Studies that were mainly performed on laboratory rats indicate that the tactile stimulation of pups at early stages of postnatal ontogenesis (before weaning) is an important factor that affects the development of the central nervous system and formation of social behavior, including parental one (Hofer 1978). In particular, it was shown that artificially reared female rats engaged in significantly fewer pup retrievals and less pup-licking and crouching as well. But, if fosterlings received increased tactile stimulation ("replacement" of maternal behaviors by the addition of simulated maternal-licking with a soft 
paintbrush), a reversal of some of the deficits was seen in adulthood (Gonzalez et al. 2001). As special studies show, tactile (somatosensory) stimulation causes changes in the frontal cerebral cortex, hippocampus, and other centers of the limbic system, and considerably affects the development of the hypothalamic-pituitary-adrenal axis (Cramer 1988; Rosenzweig and Bennet 1996; Liu et al. 1997; Post et al. 1998). The deficit of tactile stimulation leads to noticeable transformations in the development of the medial preoptic area and cerebral brain centers related to it (Numan 1994). Certain changes also occur in the development of receptor systems and secretion of several mediators and hormones, in particular, of oxytocin and vasopressin (Insel 1997; Nelson and Panksepp 1998). On the whole, this is reflected in the structure of social and especially parental behavior since the medial preoptic area is responsible for its activation (Hutchison and Steimer 1984), and oxytocin and vasopressin belong to the hormonal regulators of maternal and paternal behaviors (Reburn and Winne-Edwards 1989; Insel 1990; Wynne-Edwards 2001). Besides, both these hormones play an important role in pair-bonding (Young 1999). Thus, a high level of tactile stimulation of pups promotes an increase in subsequent parental care, especially paternal one, and reinforcement of pair-bonding; conversely, a deficit of tactile stimulation negatively affects the development of parental behavior and social relationships.

Studies carried out on species with a family-group mode of life (Elwood 1975, 1983; McGuire and Novak 1984; Solomon 1993; Clark et al. 1997; Smorkatcheva 2003; Gromov 2005a,b, 2007, 2009b) indicate that infants reared by two parents receive additional tactile stimulation from males, whereas the offspring nourished by females only in essentially solitary rodent species is devoid of such stimulation. On the basis of experiments on artificial rearing and cross-fostering of infants (McGuire 1988; Roberts et al. 1998; Gonzalez et al. 2001) as well as on the results of the experiments with Mongolian gerbil (Gromov 2009b), one may conclude that participation of males in rearing the offspring is the important factor of subsequent development in individuals of this sex of the "careful father" behavioral stereotype that is so typical of many rodent species with family-group mode of life. Moreover, additional tactile stimulation of infants promotes reinforcement of social bonds and peaceful relationships in family groups. Hence, tactile stimulation can be regarded as one of the proximate mechanisms of socialization that plays an essential role in the evolution of sociality, i.e., transition to a family-group mode of life in rodents.

Acknowledgements The study was supported by Russian Foundation for Basic Researches (grant 07-04-00142). Author is also grateful to Dr. Alexey Surov, Dr. Olga Osipova, and G. Ryurikov for assistance with keeping the animals and observations.

\section{References}

Ågren G, Zhou Q, Zhong W (1989) Ecology and social behaviour of Mongolian gerbils, Meriones unguiculatus, at Xilinhot, Inner Mongolia, China. Anim Behav 37:11-27. doi:10.1016/0003-3472 (89) $90002-X$

Armitage KB (1981) Sociality as a life-history tactic of ground squirrels. Oecologia 48:36-49. doi:10.1007/BF00346986

Arnold W (1990a) The evolution of marmot sociality: I. Why disperse late? Behav Ecol Sociobiol 27:229-237

Arnold W (1990b) The evolution of marmot sociality: II. Costs and benefits of joint hibernation. Behav Ecol Sociobiol 27:239-246

Bridges RS, Zarrow MX, Goldman BD, Denenberg VH (1974) A developmental study of maternal responsiveness in the rat. Physiol Behav 12:149-151

Brown RE, Matheison WB, Stapleton J, Neumann PE (1999) Maternal behavior in female $\mathrm{C} 57 \mathrm{BL} / 6 \mathrm{~J}$ and DBA/2J inbred mice. Physiol Behav 67:599-605. doi:10.1016/S0031-9384(99) 00109-2

Carter CS, Getz LL (1993) Monogamy and prairie vole. Sci Am 268:100-106. doi:10.1038/scientificamerican0693-100

Clark MM, Desousa D, Vonk J, Galef BG (1997) Parenting and potency: alternative routes to reproductive success in male Mongolian gerbils. Anim Behav 54:635-642. doi:10.1006/ anbe. 1997.0468

Cramer CP (1988) Experience during suckling increases weight and volume of rat hippocampus. Brain Res 470:151-155. doi:10.1016/0165-3806(88)90212-X

Dewsbery DA (1985) Paternal behavior in rodents. Am Zool 25:841852. doi: $10.1093 / \mathrm{icb} / 25.3 .841$

Dezhkin VV, D'jakov YuV, Safonov VG (1986) [European castor]. Agropromizdat, Moscow [in Russian]

Eilam D, Smotherman WP (1998) How the neonatal rat gets to the nipple: common motor modules and their involvement in the expression of early motor behavior. Dev Psychobiol 32:57-66. doi:10.1002/(SICI)1098-2302(199801)32:1<57::AID-DEV7>3.0. $\mathrm{CO} ; 2-\mathrm{S}$

Elwood RW (1975) Paternal and maternal behaviour in the Mongolian gerbil. Anim Behav 23:766-772. doi:10.1016/0003-3472(75) 90104-9

Elwood RW (1983) Paternal care in rodents. In: Elwood RW (ed) Paternal behaviour of rodents. Wiley, Chichester, pp 235-257

Francis D, Diorio J, Liu D, Meany MJ (1999) Nongenomic transmission across generations of maternal behavior and stress responses in the rat. Science 286:1155-1158. doi:10.1126/ science.286.5442.1155

Gonzalez A, Lovic V, Ward GR, Wainwright PE, Fleming AS (2001) Intergenerational effects of complete maternal deprivation and replacement stimulation on maternal behaviour and emotionality in female rats. Dev Psychobiol 38:11-32. doi:10.1002/1098-2302 (2001)38:1<11::AID-DEV2>3.0.CO;2-B

Gromov VS (2003) [Territorial structure and social organization in the Brandt vole (Lasiopodomys brandti) under semi-natural conditions]. Zool Zh 82:852-861 [in Russian with English summary]

Gromov VS (2005a) [Types of the spatial-and-ethological population structure in rodents]. Zool Zh 84:1003-1014 [in Russian with English summary]

Gromov VS (2005b) Parental care in captive Brandt vole (Lasiopodomys brandti). Russian J Theriol 4(2):137-145

Gromov VS (2007) Parental care in captive social vole (Microtus socialis). Zool Zh 86:1389-1397 [in Russian with English summary]

Gromov VS (2008) [The spatial-and-ethological structure of rodent populations]. KMK Press, Moscow [in Russian] 
Gromov VS (2009a) Parental care in captive red-backed vole (Clethrionomys rutilus). Cont Probl Ecol 2(3):11-18. doi:10.1134/ S1995425509030175

Gromov VS (2009b) Interactions of partners in family pairs, care of the offspring, and the role of tactile stimulation in formation of parental behaviour of the Mongolian gerbil (Meriones unguiculatus) under laboratory conditions. Biol Bull 36(5):479-488. doi: $10.1134 /$ S1062359009050082

Gromov VS, Surov AV, Ryurikov GB (2006) Maternal care in captive grey hamster Cricetulus migratorius (Rodentia, Cricetidae). Russ J Theriol 5(2):73-77

Gubernick DJ, Alberts JR (1987) The biparental care system of the California mouse, Peromyscus californicus. J Comp Psychol 101:169-177. doi:10.1037/0735-7036.101.2.169

Hartung TG, Dewsbury DA (1979) Paternal behavior of six species of muroid rodents. Behav Neural Biol 26:446-478. doi:10.1016/ S0163-1047(79)91500-0

Hofer MA (1978) Hidden regulatory processes in early social relationships. In: Bateson PPG, Klopfer PH (eds) Perspectives in ethology. Plenum Press, New York, pp 135-166

Hofmann JE, McGuire B, Pizzuto TM (1989) Parental care in the sagebush vole (Lemmiscus curtatus). J Mammal 70:162-165. doi: $10.2307 / 1381679$

Hutchison JB, Steimer T (1984) Androgen metabolism in the brain: behavioral correlates. Prog Brain Res 61:23-51. doi:10.1016/ S0079-6123(08)64427-1

Insel TR (1990) Oxytocin and maternal behaviour. In: Drasnegor NA, Bridges RS (eds) Mammalian parenting. Oxford, New York, pp 260-280. doi:10.1111/j.1749-6632.1992.tb34350.x

Insel T (1997) A neurobiological basis of social attachment. Am J Psychiatry 154:726-735

Kleiman DG (1977) Monogamy in mammals. Q Rev Biol 52:39-69. doi:10.1086/409721

Libhaber N, Eilam D (2004) Parental investment in social voles varies and is relatively independent of litter size. J Mammal 85:748755. doi:10.1644/BNS-011

Liu D, Diorio J, Tannenbaum B et al (1997) Maternal care, hippocampal glucocorticoid receptors, and hypothalamicpituitary-adrenal responses to stress. Science 277:1659-1662. doi:10.1126/science.277.5332.1659

Lonstein JS, De Vries GJ (1999) Comparison of the parental behaviour of pair-bonded female and male prairie voles (Microtus ochrogacter). Physiol Behav 66:33-40. doi:10.1016/S0031-9384(98)00270-4

Lonstein JS, De Vries GJ (2000) Sex differences in the parental behavior of rodents. Neurosci Biobehav Rev 24:669-686. doi:10.1016/S0149-7634(00)00036-1

McGuire B (1988) Effects of cross-fostering on parental behaviour of meadow voles (Microtus pennsylvanicus). J Mammal 69:332341. doi: $10.2307 / 1381383$

McGuire B (1997) Influence of father and pregnancy on maternal care in red-backed voles. J Mammal 78:839-849. doi:10.2307/1382942

McGuire B, Novak M (1984) A comparison of maternal behaviour in the meadow vole (Mictotus pennsylvanicus), prairie vole ( $M$. ochrogaster) and pine vole (M. pinetorum). Anim Behav 32:1132-1141. doi:10.1016/S0003-3472(84)80229-8

McGuire B, Novak M (1986) Parental care and its relation to social organization in the montane vole. J Mammal 67:305-311

Nelson E, Panksepp J (1998) Brain substrates of infant-mother attachment: contributions of opioids, oxytocin and norepinephrine.
Neurosci Biobehav Rev 22:437-452. doi:10.1016/S0149-7634(97) 00052-3

Numan M (1994) Maternal behavior. In: Knobil E, Neill JD (eds) The physiology of reproduction. Raven Press, New York, pp 221-302

Oliveras D, Novak M (1986) A comparison of paternal behavior in the meadow vole, Microtus pennsylvanicus, the pine vole, Microtus pinetorum, and prairie vole, Microtus ochrogaster. Anim Behav 34:519-526

Post RM, Weiss SR et al (1998) Neural plasticity and emotional memory. Dev Psychopathol 10:829-855. doi:10.1017/S0954579498001898

Proulx G, Gilbert FF (1983) The ecology of the muskrat, Ondatra zibethicus, at Luther Marsh, Ontario. Can Field-Nat 97:377-390

Reburn CJ, Winne-Edwards KE (1989) Hormonal changes in males of a naturally biparental and a uniparental mammal. Horm Behav 35:163-176. doi:10.1006/hbeh.1998.1509

Roberts RL, Williams JR, Wang AK, Carter CS (1998) Cooperative breeding and monogamy in prairie voles: influence of the sire and geographic variation. Anim Behav 55:1131-1140. doi:10.1006/ anbe.1997.0659

Rosenblatt GS, Lehrman DS (1963) Maternal behaviour of the laboratory rat. In: Rheingold HL (ed) Maternal behaviour in mammals. Wiley, London, pp 8-57

Rosenzweig MR, Bennet EL (1996) Psychobiology of plasticity: effects of training and experience on brain and behavior. Behav Brain Res 78:57-65. doi:10.1016/0166-4328(95)00216-2

Rowell TE (1961) Maternal behaviour in non-lactating golden hamsters. Anim Behav 9:11-15

Shilton CM, Brooks RJ (1989) Paternal care in captive collared lemmings (Dicrostonyx richardsoni) and its effect on development of the offspring. Can J Zool 67:2740-2745. doi:10.1139/ z89-388

Smorkatcheva AV (2003) Parental care in the captive mandarin vole, Lasiopodomys mandarinus. Can J Zool 81:1339-1345. doi:10.1139/z03-100

Sokal RR, Rohlf FJ (1995) Biometry, 3rd edn. Plenum Press, New York

Solomon NG (1993) Comparison of parental behaviour in male and female prairie voles (Microtus ochrogacter). Can J Zool 71:434 437. doi:10.1139/z93-061

Svendsen GE (1980) Population parameters and colony composition of beaver (Castor canadensis) in southeast Ohio. Am Midl Nat 104:47-56. doi: $10.2307 / 2424957$

Thomas JA, Birney EC (1979) Parental care and mating system of the prairie vole, Microtus ochrogaster. Behav Ecol Sociobiol 5:171186. doi:10.1007/BF00293304

Wang ZX, Insel TR (1996) Parental behavior in voles. Adv Study Behav 25:361-384. doi:10.1016/S0065-3454(08)60338-1

Wilson SC (1982) Parent-young contact in prairie and meadow voles. J Mammal 63:300-305. doi:10.2307/1380642

Wynne-Edwards KE (2001) Hormonal changes in mammalian fathers. Horm Behav 40:139-145. doi:10.1006/hbeh.2001.1699

Xia X, Millar JS (1988) Paternal behavior by Peromyscus leucopus in enclosures. Can J Zool 66:1184-1187. doi:10.1139/z88-173

Young LJ (1999) Oxytocin and vasopressin receptors and speciestypical social behaviors. Horm Behav 36:212-221. doi:10.1006/ hbeh. 1999.1548

Zorenko TA (1994) Ethology. In: The common vole: sibling species Microtus arvalis Pallas, 1779 and M. rossiaemeridionalis Ognev, 1924. Nauka Publ, Moscow, pp 289-297 [In Russian] 